\title{
UMA FORMA DE FORMAÇÃO: MÉDICOS NA ESCOLA PROFISSIONAL
}

Maria Stephanou*

SINTESE - O estudo examina um dos modos de realização da formação sanitária empreendida por médicos gaúchos junto a uma escola técnicoprofissional para trabalhadores, nas primeiras décadas deste século, no Rio Grande do Sul. Busca-se demonstrar que as ações e estratégias desencadeadas pelos médicos conferiram uma forma, uma identidade ao processo de formação, forma essa associada à constituição de sujeitos com consciência sanitária e comportamento higiênico. A investigação volta-se para a extensa rede de saberes e poderes que elegeu a escola como locus privilegiado de atuação de higienistas que associaram a prática da higiene a um ideal de civilidade, urbanidade e progresso.
ABSTRACT - The study examines one of the ways of realization of the sanitary formation carried out by doctors from Rio Grande do Sul at a technical-professional school for workers, in the first decades of this century in the above referred State. We seek to show that the actions and strategies unleashed by the doctors have conferred a form, an identity to the formation process. This form is associated to the constitution of subjects with sanitary conscience and behavior. The investigation is directed towards the broad net of knowledge and power which chose the school as a privileged locus of action for sanitarists, associating the practice of sanitarism to an ideal of civility, urbanity and progress.

Neste artigo, proponho-me a problematizar e descrever um dos modos de realização da formação sanitária empreendida pelos médicos gaúchos nas primeiras décadas deste século. A investigação se desenvolve no âmbito de um projeto de pesquisa, interdisciplinar e inter-institucional, que visa reconstituir o processo de formação dos habitantes de cidades gaúchas, assim como os principais saberes instaurados a partir desse processo, no decorrer do século XX.

Historiadora. Mestre em Educação. Doutoranda em Educação. Professora da Faculdade de Educação da Universidade Federal do Rio Grande do Sul. Pesquisadora do Projeto Integrado "Urbanidade e Cidadania: processos de formação e instauração de saberes", que se desenvolve interinstitucionalmente (UFRGS, PUCRS e UNISINOS), com apoio do CNPq e da F'APERGS.

\begin{tabular}{|l|l|l|l|l|l|}
\hline VERITAS & . Porto Alegre & v. 42 & $\mathrm{n}^{2} 2$ & Junho 1997 & p. 291-306 \\
\hline
\end{tabular}


O estudo examina a atuação do Departamento de Saúde da Escola Engenharia de Porto Alegre, ${ }^{1}$ no periodo de 1919 aos anos 30. Esta atuação privilegiou 0 Instituto Parobé, instituto filiado à Escola, voltado ao ensino técnico-profissional de trabalhadores.

No âmbito da história da educação brasileira, é indiscutivel a relevância do Instituto Parobé dentre o conjunto das instituições educacionais para trabalhadores no Rio Grande do Sul, constituindo um caso exemplar neste período, cujo reconhecimento extrapolou a esfera regional. ${ }^{2}$

O Departamento de Saúde empreendeu ações visando os serviços de assistência médica, inspeção de saúde, educação sanitária e adoção de preceitos da Higiene nos Institutos e estabelecimentos da Escola de Engenharia de Porto Alegre. Detenho-me em alguns dos aspectos deste amplo espectro de atuação do Departamento. Tal atuação é concebida como prática formativa, dirigida aos agentes envolvidos na instituição: professores, funcionários, alunos e suas familias.

Busco compreender como a formação empreendida pelos médicos nesta escola profissional, envolveu os alunos-trabalhadores e demais agentes, no intuito da constituição de sujeitos portadores de consciência sanitária e comportamento higiênico, atributos presentes nas práticas discursivas que buscavam expressar as exigências de uma sociedade urbano-industrial.

Neste estudo, pareceu-me instigante incorporar a idéia de formação e não apenas de educação sanitária. Não se trata de adotar uma tendência nominalista tão somente, ou ainda de proceder a uma incorporação reificada de conceitos. Como sugere Veyne (apud Carvalho e Lima,1992:121), trata-se de construir diferenças e não equivalências, comuns em análises nas quais os conceitos assumem um valor explicativo absoluto, um uso meramente instrumental, "pouco importando a explicitação das condições da própria configuração". Explico-me: o vocábulo formação via de regra não é empregado nos discursos da época a ser analisada. Contudo, emprega-se educação, de forma ampliada, demonstrando o quanto ela deveria abranger as múltiplas dimensões do educando. Fala-se por vezes em educação integral: educação física, intelectual e moral. ${ }^{3}$

1. A Escola de Engenharia de Porto Alegre foi inaugurada em 1897, nos moldes de uma Universidade Técnica propugnada por Augusto Comte. Desde sua origem esteve intimamente ligada ao Partido Republicano Riograndense - PRR, de forte influência positivista. Caracterizada como de iniciativa particular, contou com substanciais subvenções regulares dos governos estadual e municipal e de industriais gaúchos, constituindo uma propriedade pública por seus bens presentes e futuros. Ao longo de sua trajetória instalou diversos institutos filiados, uns destinados ao ensino superior e outros ao ensino técnico-profissional. O presente estudo detém-se no Instituto Técnico-Profissional inaugurado em 1906 e denominado Instituto Parobé a partir de 1917. O Parobé voltou-se para a instrução de meninos pobres, filhos de operários e operários em busca de aperfeiçoamento. Ainda em 1920, O Instituto Parobé instalou um curso feminino. Este Instituto, tanto a sua divisão masculina quanto a feminina, mereceu atenção destacada do Departamento de Saúde. Ver a respeito Stephanou, 1990.

2 Em 1920 o engenheiro chefe do Instituto Parobé, Dr. João Luderitz foi convocado pelo governo federal para dirigir o Serviço de Remodelação do Ensino Profissional no país, tendo como instituição exemplar o Parobé (Ver Stephanou, 1990:369).

3 Em 1920, aponta-se literalmente os três componentes da formação - o coração, o espínito e 0 caráter. Assim aparece no Relatório da Escola de Engenharia (1920:483 grifo meu), instituição que neste periodo contava com um Departamento de Saúde. 
Faz-se aqui a apropriação da categoria formação no sentido de "instauração de um conjunto de disposições de saber-ser, de atitudes, de hábitos, de pensamentos e de expectativas adquiridas simultaneamente em tal processo, envolvendo, então, socialização (incorporação do habitus") e integração progressiva dos formados no contexto social em que se encontram inseridos" (Tanguy,1986:100). É neste sentido que tomo as práticas formativas encetadas pela medicina, já que intento demonstrar que elas incidiram sobre o "saber-ser" e o "saber-fazer" dos indivíduos, em especial quanto aos saberes relacionados à higiene e saúde. Saberser e saber-fazer implicados nos modos de conhecimento e cuidado de si que constituem os sujeitos. Em outras palavras, no modo particular pelo qual as pessoas se descrevem, se narram, se julgam ou se controlam a si mesmas (Larrosa, 1994).

As ações e estratégias desencadeadas pelos médicos através do Departamento de Saúde, conferiram uma forma, uma identidade peculiar ao processo de formação. Esta identidade, como apresento a seguir, esteve associada a práticas de auto-cuidado, em especial de higiene pessoal, de saúde mental e de conduta moral adequada. ${ }^{5}$

A idéia de constituição de sujeitos higiênicos implicou interrogar como e em que medida a escola, enquanto lugar de formação, através do "dispositivo de higiene e saúde" produziu novos modos de conhecimento de si e de relação de si para consigo dos alunos-trabalhadores.

Importante relembrar que as estratégias de saneamento pela educação, no periodo em estudo, guardam especificidades no que se refere à população pobre. Era preciso higienizá-la, mas também purificá-la para fazer frente aos riscos da degeneração. Fez-se uma intima associação entre o discurso higienista e os princípios eugenistas que, especialmente a partir dos anos 20, no Brasil, se disseminaram entre os cientistas-intelectuais do país.

A preocupação com a degeneração da raça engrossou os argumentos que elevavam a educação popular ao patamar de única solução. Através da educação seria possível concorrer para o "saneamento da raça, tornando-a forte e válida, capaz de vencer na grande competição mundial". A presença pública cada vez maior de agentes do campo médico nas discussões e adoção de medidas públicas com vistas a uma pretensa construção de um "corpo social sadio" vêm a indicar a maneira como o conhecimento da medicina atuou de forma considerável, específica, no processo de formação das populações, em especial os trabalhadores das cidades.

1 Habitus no sentido que lhe é atribuido por Bourdieu, qual seja como "[...]sistema de disposições duráveis e transponiveis, estruturas estruturadas, predispostas a funcionar como estruturas estruturantes [...]" (1980:80). As estruturas mentais do sujeito são produto das suas relações com o mundo social. Posso entender assim, que as práticas sociais (históricas) produzem e reproduzem também modos de ser e relações para consigo (elementos integrantes do habitus), ainda porque 0 habitus, segundo o autor, envolve um sistema de produção de práticas e um sistema de esquemas de percepção e apreciação das práticas (1987). Parece-me, assim, não haver uma irremediável incompatibilidade deste conceito com os modos de subjetivação teorizados por Foucault e que no que tange às técnicas de si perpassam este ensaio.

- Para descrever estas práticas, lancei mão de fontes primárias tais como relatórios e publicações do Departamento de Saúde, currículos das disciplinas de educação sanitária, conferências e artigos de médicos da escola, apreciações de visitantes diversos, entre outros materiais. 
Esse caráter regenerador fez-se presente nos propósitos da educação sanitária do Instituto Parobé, afinal, tratava-se de plasmar vigorosos e produtivos trabalhadores nacionais.

\section{O Departamento de Saúde e a formação do cidadão trabalhador}

O Departamento de Saúde da Escola de Engenharia de Porto Alegre, criado pelo ato $\mathrm{n}^{2} 39$ de 12 de junho de 1919, estendeu sua atuação pelo menos até 1934, quando da criação da Universidade de Porto Alegre, que incorporou a Escola de Engenharia e demais cursos superiores, reestruturando administrativamente a instituição.

Cabe ressaltar, contudo, que a criação do Departamento representou a institucionalização de um serviço que já vinha sendo realizado pelo professor da Escola, o médico Dr. João Pitta Pinheiro, desde 9 de maio de 1902. O período que entremeia 1902 e a criação do departamento expressa a importância e o reconhecimento que a atuação deste médico pode acumular, bem como o crédito de que era possuidor num momento histórico em que o capital simbólico do campo médico vinha se consolidando. De outra parte, o discurso médico inscrevera-se na política geral de verdade daquele momento, sendo-lhe possivel produzir o que Foucault chamou de efeitos regulamentados de poder (1993a:12). Assim, pode-se afirmar que o Dr. Pitta Pinheiro contou com um reconhecimento (dentro e fora da escola) suficiente para ter condições de impor esse reconhecimento através da oficialização de suas ações na escola. ${ }^{6}$ Émbora clinicando sistematicamente, dedicou-se à medicina social, atuando em obras filantrópicas, como o Asilo Padre Cacique, e ainda destacando-se como professor não só em Institutos da Escola de Engenharia, mas também junto ao Curso de Aperfeiçoamento da Escola Normal, lecionando Psicologia Experimental aplicada à educação. Desta maneira, pode incorporar ao seu reconhecimento tanto o atributo de excelente médico, quanto de respeitável educador. Este duplo perfil foi bem explorado pelo Dr. Pitta ao advogar os requisitos necessários ao cumprimento da função de médico-escolar.

Durante todo o periodo de existência do Departamento de Saúde, e mesmo antes, o Dr. João Pitta Pinheiro? atuou como chefe dos serviços médicos prestados na Escola. A partir de 1919, na condição de Médico Assistente, seu filho, o Dr. Carlos Pitta Pinheiro acompanhou as atividades do departamento. Contou ainda

6 A legitimidade do campo médico está associada ao poder simbólico, assentado num capital simbólico que ele conquistou. (Bourdieu,1987:166-7). Ou, como sugere Foucault, aos médicos esteve assegurada a atribuição de competência, no regime geral de verdade produzido naquele momento histórico (1993a:12).

7 A familia dos Pitta Pinheiro (pai, filho, netos) constituiu gerações de médicos gaúchos que atuaram em serviços de saúde em diversas instituiçōes educacionais, asilares e assistenciais. Identificou-se que o Dr. Pitta Pinheiro conferiu uma marca pessoal ao Depto: inovação constante, conhecimento e acompanhamento sistemático das produções européias, especialmente dos higienistas franceses, domínio da área "Higiene". A legitimidade das açōes que empreendeu no espaço escolar deveuse, ainda, à ratificação das mesmas por parte de outros agentes sociais do campo médico. Tendo exercido função pública na administraçăo estadual por mais de 35 anos, sendo inclusive diretor do Gabinete Médico Legal da Chefatura de Polícia, esteve intimamente associado ao campo do poder. Na Escola de Engenharia, recebeu visitas sistemáticas de dirigentes e professores da Faculdade de Medicina de Porto Alegre, que registravam o apoio ao trabalho do Dr. Pitta Pinheiro. 
com um dentista, uma enfermeira visitadora e enfermeiros nos Institutos com internatos.

Desde sua instalação, o Departamento de Saúde constituiu o departamento da Escola de Engenharia destinado aos serviços de assistência médica aos alunos gratuitos e funcionários da Escola, de inspeção de saúde e de tudo que se referisse à Higiene nos seus Institutos e Estabelecimentos. Para o médico-chefe,

"O fim deste Departamento, numa Instituição como esta, é pois, proporcionar, com facilidade aos nossos companheiros e aos nossos alunos, não só o tratamento de que careçam, quando enfermos, mas ainda, e principalmente, cuidar do seu desenvolvimento físico, elemento básico do desenvolvimento de uma raça e mais, evitando as moléstias evitáveis, curando outras ou aliviando sofrimentos físicos, quando mais não se possa fazer" (Relatório, 1925:4).

As ações do Departamento não se restringiram ao atendimento dos casos de doença. O Dr. Pitta Pinheiro persistiu na implementação de ações de cunho profilático convicto de que essas são sempre mais indicadas quanto ao bem geral, do que as medidas curativas, que são individuais (Relatório, 1920:3). Além do mais, a profilaxia viria ao encontro dos propósitos eugênicos explicitados nos objetivos do Departamento.

As medidas profiláticas consistiam na fiscalização sistemática quanto à higiene, dos prédios, indivíduos e alimentação. Para tanto, houve na escola uma intensa presença dos médicos, de forma quase onipresente. Um olhar atento e vigilante sobre a circulação e distribuição dos corpos. As inspeções e intervenções superaram uma periodicidade preestabelecida e foram ampliando progressivamente as esferas de atuação do Departamento.

O acompanhamento das iniciativas do Departamento de Saúde através do tempo permite captar como o mesmo foi se complexificando, à medida que legitimava-se na escola e fora dela. Permite ainda verificar a sintonia dos agentes com as estratégias empreendidas tanto pelo campo da medicina, quanto pela esfera educacional voltada aos trabalhadores, no sentido de cercamento de suas experiências.

Atento em relação à produção de higienistas franceses, evocados como argumentação respeitável nos relatónios do Departamento, o Dr. Pitta Pinheiro explicitou a magnitude do projeto da Higiene. Toda uma teia de observações e saberes buscou cercar as experiências oportunizadas aos alunos na escola, com o intuito de infiltrar-lhes uma consciência sanitária e comportamentos higiênicos.

Assim, tendo iniciado com os exames de saúde de cada aluno, o Departamento de Saúde acabou implementando novas ações na escola: inspeção médica escolar, organização fisiológica do trabalho nas oficinas do Instituto Parobé, exames psicotécnicos, enfermeiras visitadoras, boletins semanais de saúde, preleções, cursos, etc., ampliando significativamente sua influência na forma do processo de formação da Escola.

Apenas para ilustrar a ampliação dos serviços prestados pelo Departamento, enquanto em 1920 o movimento do consultório havia sido de 250 consultas, em 1925 o mesmo movimento representou 1619 consultas (Relatório, 1925:4).Há uma relação destes dados com o aumento do contingente de alunos na Escola, mas há 
também uma vinculação com a complexificação dos dispositivos de atuação do Departamento que,

"foi limitado a princípio a um simples serviço de Saúde e dai alçou-se a um Departamento pelo qual nele vem correndo e nele se concentrando todos os serviços, atos e resoluções sobre higiene, saúde, inspeção, clínica e educação fisica e sanitária"."

O caráter educativo do Departamento foi se consolidando no decorrer do tempo, impulsionado pelas teses higienistas que insistiam em procedimentos de controle individual e coletivo, de maneira a assegurar a reeducação higiênica de toda a sociedade, em especial das classes populares.

Igualmente, as ações formativas do Departamento de Saúde recaíram sobre aqueles Institutos da Escola de Engenharia que destinavam-se a alunos e alunas trabalhadoras. O Instituto Parobé, sua divisão masculina e feminina, foi prioritariamente acompanhado pelos serviços de saúde da Escola. Os propósitos da educação sanitária encontravam-se amplamente contemplados na proposta educacional do Instituto: "promover a educação de um operariado nacional, sob o ponto de vista físico, moral e instrutivo, preparando pessoal idôneo para as indústrias, concorrendo para a cultura moral, sentimento pátrio e instrução profissional". ' O propósito de uma educação que extrapolasse o "saber-fazer" abriu espaço para a intervenção dos médicos-educadores, interessados na produção de um novo "saber-ser".

\section{As formas da formação}

A eficácia da ação médica está diretamente relacionada com os dispositivos utilizados no processo de formação, nas experiências e saberes oferecidos aos alunos. Assim, não seriam apenas exames de saúde ou preleções nas aulas, mas um amplo espectro de intervenção que asseguraria os propósitos de reeducação. 0 Departamento de Saúde não tardou a explicitar esta perspectiva. Progressivamente inaugurou práticas complexas de formação dos alunos, professores, funcionários e suas famílias. Elas consistiram em: uma rotina definida minuciosamente, que pela repetição pudesse ser incorporada aos modos de ser e pensar dos alunos; o exame individual e a observação (vigilância) contínua que detectasse os desvios e problemas a tempo de serem tratados tão logo identificados; a veiculação sistemática de informações e preceitos, seja através do curso de educação sanitária, seja em consultas individuais, seguidas de conselhos e advertências, seja em boletins semanais afixados ou em boletins distribuídos, seja nas visitas e preleções junto às familias.

A intervenção dos médicos foi igualmente intensa no esquadrinhamento dos alunos, incidindo sobre os aspectos físicos, psíquicos/intelectuais, morais, de forma a erradicar maus hábitos herdados da família ou da tradição, corrigir práticas defeituosas, instaurar novos comportamentos e prevenir outros. Erradicar, corrigir, instaurar e prevenir adjetivam em linhas gerais a forma da formação encetada pelos médicos no Parobé.

Cf. Art. 79 dos Estatutos da Escola de Engenharia. In: Relatório, 1930:1.

$\rightarrow$ Cf. Relatório apresentado ao Conselho Municipal pelo Intendente de José Montaury, 1910:131. 


\section{Todos e cada um: os diferentes cuidados da formação}

As inspeções de saúde representaram, inicialmente, a atividade mais importante do Departamento. Consistiam em inspeções de saúde dos candidatos aos internatos, à matrícula ou à admissão como funcionários, antes dos demais exames de admissão.

Estas inspeções permitiam realizar a seleção do pessoal sob o ponto de vista da Higiene, excluindo-se aqueles cujo estado de saúde não permitisse os trabalhos práticos dos Estabelecimentos, ou cuja permanência seria nociva à coletividade. Segundo o médico-chefe, "assim é que temos tido grupos de alunos gozando perfeita saúde” (Relatório, 1919:4).

De certa maneira, travestidos em discurso médico-científico, preconceitos e estereótipos sociais contribuíram para a exclusão de alguns outros, explicitando o perfil de aluno e funcionário ideal.

Periodicamente, os alunos e funcionários eram submetidos a exames médicos e odontológicos no Gabinete médico da escola. O médico responsável elaborava uma ficha individual para cada aluno registrando todas as ocorrências de sua saúde. Os alunos portadores de doenças eram afastados da escola quando o tratamento fugia da alçada do Departamento de Saúde. Os demais casos eram tratados na própria escola. Procurava-se desta forma salvaguardar a saúde individual e coletiva, no intuito de constituir "agremiações sadias".

Este serviço incluía ainda exames junto aos requerentes de licenças ou faltantes, por alegado motivo de doença ou para emissão de atestados de saúde para fins diversos. No consultório, realizava-se o registro do movimento clínico com anotação da natureza do serviço prestado, idade do paciente, profissão, Instituto de origem e resultado do tratamento (cf. Relatório, 1922:4).

A observação acurada e sistemática de cada um e de todos caracterizou o exame como dispositivo fundamental da disciplina e do controle, permitindo qualificar, classificar e excluir aqueles que pudessem constituir perigo à coletividade. ${ }^{10}$

O Dr. Pitta Pinheiro, em vários relatórios, referia-se às Carteiras de Saúde ou aos livros de registro do Consultório, onde poderiam ser comprovadas as atividades e a eficácia dos procedimentos individuais prescritos e das orientações educativas empreendidas pelo médico junto ao paciente. A defesa de outras práticas não desconsiderou jamais a importância dos exames.

Articulavam-se, dessa maneira, procedimentos individuais e coletivos, concorrendo um para a consecução do outro. A par das consultas e exames, a inspeção de saúde incluiu visitas ordinárias e regulares aos Institutos, enfermarias e internatos, bem como visitas extraordinárias, por solicitação ou emergência. A presença dos médicos fez-se continua.

As inspeções de saúde, e mais tarde as inspeções médico-escolares, possibilitaram aos médicos intervir inclusive nas bases de gestão material da escola, seja nas questões físicas do prédio, ventilação, iluminação, seja na distribuição dos corpos e na circulação dos agentes, implicando muitas vezes a definição do projeto pedagógico do Instituto.

10 Parte-se aqui da concepção de exame formulada por Foucault, 1993b:164-165. 
De outra parte, a expressividade dos exames individuais e coletivos constituíram terreno fértil para a constituição de saberes e de poderes," dentre os quais a autoridade conquistada pelos médicos de classificar o são e o doente, o normal e 0 anormal, o higiênico e o sujo, o útil para a coletividade e o desprezivel.

Cuidados com todos e com cada um, através desses exames periódicos, constituiu uma "tecnologia pastoral" de gestão dos envolvidos, conduzindo-se seus gestos, atitudes, pensamentos e valores de forma minuciosa e atenta.

A julgar pelos relatos, as inspeções e consultas, enquanto olhar acurado e assíduo dos médicos, constituiu-se em estratégia essencial aos propósitos de higienização da escola e de cada um.

\section{Inspeção médico-escolar para uma agremiação sadia}

A inspeção médico-escolar ${ }^{12}$ constituiu um aperfeiçoamento das inspeções de saúde, incorporando através do tempo a experiência e os saberes produzidos por esta prática.

Foi inaugurada em 1919, junto ao Instituto Parobé, não se limitando à inspeção periódica dos alunos e de candidatos, mas também a inspeção das aulas, instalações, propondo as alterações que a ciência e a prática aconselhassem.

Defendendo as teses de higienistas famosos o Dr. Pitta Pinheiro concordava com a centralidade da escola na vida social, e com a importância de

"fazer da escola uma instituição em que a saúde dos alunos seja vigiada com atenção, em que o seu desenvolvimento físico seja objeto de tantos cuidados quanto seu desenvolvimento intelectual e onde eles tomassem exemplos e hábitos de higiene que mais tarde poderiam também aplicar a sua familia". (Relatório, 1922:9-10, grifos meus).

A complexidade da inspeção escolar, assinalada pelos médicos do Departamento, constituiu um elemento poderoso para o reforço de seu estatuto na escola. Era tarefa que não podia ser desempenhada por qualquer agente, tampouco por qualquer médico, uma vez que

1 O dispositivo do exame permite levantar um campo de conhecimentos sobre os examinados. Este certo tipo de formação de saber remete a uma certa forma de exercício do poder (Foucault, 1993b:166).

12 Segundo o Dr. Pitta Pinheiro, “a Inspeção Escolar, entre nós, è feita logo à entrada dos alunos e no correr do ano são reinspecionados 2 a 3 vezes, conforme as circunstâncias do seu estado de saúde. Várias vezes assim temos tido a oportunidade de ser úteis à coletividade e ao próprio indivíduo, ora aconselhando-lhe medidas úteis, ora impondo medidas, no sentido de salvaguardar a coletividade. Em tais circunstâncias é forçoso convir, o papel de médico escolar, por vezes é pouco agradável, mas atendo-se a importância da missão que lhe é confiada, todos esses dissabores se transformam na satisfação de uma bela prática, cumprindo um dever social. Entre nós, isto é, em o nosso grupo de alunos, não existe moléstia escolar, pois todos os alunos são previamente inspecionados, selecionados, isolados quando necessário e tratados convenientemente quando aceitam os nossos oferecimentos, de modo que em tais condiçōes, cientes das nossas inspeçōes nem sequer tem, como dantes, as cabeleiras povoadas de parasitas e nos tem dado a oportunidade de, após tantas inspeções, podermos dizer que no grupo escolar da Escola de Engenharia não há moléstia escolar (Relatório, 1925:9, grifos meus). 
"não basta para ser médico escolar, possuir um diploma ou ser clínico, é preciso sobretudo uma grande experiência e tino para poder tirar, em tempo, todas as vantagens da Inspeção" (Relatório, 1923:11).

Reunindo em sua trajetória larga experiência tanto como médico, quanto como educador, o Dr Pitta Pinheiro e seu filho, médico-assistente, reuniram condições para implementar novas responsabilidades do Departamento de Saúde, intensificando suas intervenções no processo de formação.

Assim, em 1921, a "grande experiência e tino dos médicos" do Departamento de Saúde reelaborou a estruturação do serviço de inspeção médica, introduzindo um Serviço Regular de Higiene Escolar, extensivo às alunas da seção feminina do Parobé. O serviço contou com a atuação das denominadas Enfermeiras Visitadoras às quais era reservada a atividade de visitas sistemáticas às famílias de alunos e funcionários com o fim de reforçar a ação benéfica do médico na escola.

$\mathrm{O}$ entendimento de que os alunos eram herdeiros de uma educação defeituosa remete à difusão da idéia de "nocividade do meio familiar" presente no discurso médico desde o final do século XIX e que "constitui o grande trunfo médico na luta pela hegemonia educativa das crianças" (Freire Costa,1983). Neste particular, - Departamento de Saúde traçou diferentes estratégias objetivando evitar a diluição da ação benéfica, corretiva e preventiva do médico na escola pelo contato com as práticas familiares, sem descuidar da extensão do projeto educativo até junto das familias: enfermeiras visitadoras, boletins de saúde, visitas domiciliares do médico assistente em caso de doença e para prestar as orientações adequadas, constituiram práticas encetadas para a reeducação da sociedade através do acompanhamento das familias.

"É preciso não esquecer que, um elemento poderoso e contrário ao êxito das Inspeções Escolares, é a ignorância de uma grande parte dos pais dos alunos, que vivem num meio intelectual acanhado e por vários motivos imbuídos de preceitos e preconceitos os mais estranhos, pelo que, com raras exceções e grandes dificuldades, se pode contar com a sua aquiescência para a prática de medidas úteis. Em tais condições, e para sanar tanto quanto possivel tais faltas, é que se tem mantido um corpo de "Enfermeiras Visitadoras" (Relatório, 1923:3, grifos meus).

A Enfermeira Visitadora, denominada a partir de 1928 de "Guardiã da Saúde", esteve encarregada da distribuição dos Boletins de Saúde às famílias de alunos e funcionários, acompanhando-as e transmitindo conselhos de ordem higiênica, informando aos médicos suas observações, em cumprimento às determinações expressas do Departamento de Saúde. Por vezes, o Dr. Pitta Pinheiro destacava informes da Enfermeira, nos quais a mesma notava junto às famílias não só o interesse em conhecer os assuntos tratados nos Boletins, mas também as melhoras das casas no ponto de vista higiênico, apesar da modéstia das mesmas.

Os médicos do Departamento de Saúde prescreviam minuciosamente as atribuições da enfermeira visitadora. Interessou-lhes sobremaneira não só a vigilância que ela exerceu sobre as condutas familiares, mas especialmente a rede de informações que ela viabilizou entre o Departamento e as famílias: estender o olhar médico para dentro das casas, extraindo saberes; levar às casas explicações complementares, minuciosas, quanto a comportamentos e hábitos de urbanidade e civilidade a desenvolver. Aqui, de uma maneira mais clara, pode-se perceber essa 
espécie de transbordamento da escola, tanto na difusão de conhecimentos, quanto no trabalho de codificação e normatização das condutas realizado pelos saberes médicos, em especial aos trabalhadores da cidade.

\section{Informar para formar: novos saberes para novas práticas}

O acompanhamento da trajetória do Departamento de Saúde permite destacar a importância atribuída pelos médicos à propaganda e difusão de novos conhecimentos para a reeducação segundo os moldes da Higiene. É possivel identificar um empenho sistemático desses agentes na produção de materiais instrutivos e na formalização desses conhecimentos por meio de sua adoção no currículo dos cursos oferecidos pelos Institutos.

Através de cursos, preleções e publicações diversas, o Dr. Pitta Pinheiro tratou de assuntos de Higiene, de interesse da coletividade, "em linguagem clara e acessivel aos menos inteligentes, noções sobre os meios de evitar as moléstias" (Relatório, 1924:5), sobre higiene alimentar, sobre práticas físicas adequadas, conduta moral e sexual.

As preleções aos alunos e professores abordavam os mais diferentes assuntos relacionados à Higiene. Semanalmente, realizavam-se conferências junto à seção feminina do Parobé, acorrendo também alunas e professoras. Uma professora era orientada pelo médico para desenvolver mais detidamente com as alunas os assuntos abordados, em especial seu caráter prático, de forma a envolvê-las ativamente.

Os Boletins Sanitánios, com publicação sistemática, eram distribuídos aos alunos, funcionários e suas famílias, remetidos pelo correio ou entregues em pessoa pela Enfermeira Visitadora, que já bem orientada sobre o texto destes Boletins explicava a prática das medidas aí aconselhadas (Relatório, 1925:6). Acessivel e ilustrado, de forte cunho moral, o Boletim visou antes de mais nada normatizar e prescrever fórmulas precisas, condutas de indiscutivel eficiência higiênica. Através de histónias ou alusões a fatos concretos, buscava transmitir um ideal de civilidade, acentuando as vantagens advindas de práticas adjetivadas de modernas, as quais era inconcebível ignorar.

O Dr. Pitta Pinheiro, em vários relatórios, destacou a repercussão positiva dos boletins

"Que este trabalho não tem sido inútil, provam, não só o interesse que tenho notado pela leitura desses Boletins, pedindo-se às vezes explicaçōes sobre alguns pontos, ora se fazendo referências a eles em várias ocasiões, e sobretudo, o estado sanitário do nosso pessoal, as continuadas melhoras nas suas vivendas, muitas vezes bem modestas, mas na sua quase unanimidade bem asseadas, como nos tem feito referência a Enfermeira Visitadora" (Relatório, 1925:6, grifos meus).

Paralelamente aos Boletins Sanitários, produziram-se Boletins de Saúde (semanais) afixados em quadro apensos nas diversas dependências da Escola e Institutos, escolhidos os lugares de mais freqüência, nos quais se liam conselhos de Higiene, de interesse individual e coletivo. 
Para ambos, Boletins Sanitários ou de Saúde, julgava-se que "alguma coisa de útil há de ficar na consciência do seu leitor, descrente ou mordaz" (Relatório, 1924:5).

A partir de 1924, o Departamento de Saúde empreendeu uma nova frente de atuação. Passou a publicar na Egatea - revista da Escola de Engenharia de Porto Alegre, de circulação em todos os Institutos e na sociedade em geral, diversos artigos assinados pelos médicos do departamento. Também garantiu na mesma revista uma coluna fixa, intitulada Seç̧ão de Profilaxia do Departamento de Saúde da Escola de Engenharia. No primeiro caso, artigos de fundo, de difusão do ideário da medicina social e de divulgação de temas abordados por eminentes higienistas da época, especialmente franceses. Já na secção de profilaxia, breves textos, de no máximo dois parágrafos, voltados para o esclarecimento de dúvidas, propaganda e preceitos higiênicos práticos, em assuntos variados: sífilis; fadiga do trabalho; higiene alimentar; limpeza das mãos e banhos diários; importância da ventilação e iluminação; prática de esportes; vestuário asseado; boa educação moral; normas para construções higiênicas; importância da mulher no lar; a escola higiênica; importância dos exames psíquicos e psicotécnicos, dentre muitos outros. $\mathrm{O}$ aspecto normativo é a tônica destes pequenos textos, taxativos quanto ao que se deve ou não se deve fazer, quanto aos cuidados a serem dispensados para consigo e a importância de acrescentá-los à rotina diánia. Não comportavam dubiedade e requeriam uma atitude, uma adesão pessoal imediata. Em 1929, é emblemático o artigo intitulado asseio corporal, no qual se dizia:

\begin{abstract}
“O asseio corporal é uma necessidade imprescindivel a todo indivíduo. A saúde não poderá ser feita, nem estar o homem preparado convenientemente para resistir às suas alterações quando se trata de individuos desasseados. Há milhões de pequenos poros pelos quais se faz a extravasão das impurezas do sangue e que impedidas de sair pela pele vão eliminarse pelas urinas, sobrecarregando a função dos rins. A pele pois, deve ser mantida sempre bem lavada e com sabão, e principalmente as partes expostas, cabeça, pés e mãos. As mãos devem ter cuidados especiais de asseio porque é por elas que em geral se transportam as poeiras nocivas. Enfim é bom ter em mente o que sobre esse assunto diz Jules Payot, reitor da Academia de Paris: "O homem sujo não é um perigo somente para si, é um perigo público" (Egatea, v. XIV, n.1-2, 1929:4, grifos meus).
\end{abstract}

Dois aspectos ainda podem ser ressaltados: um, relativo ao tom cientificista, portanto "verdadeiro", das recomendações veiculadas; outro, concernente, mais uma vez, à preocupação em aliar o individual com o coletivo. O sujo prejudica a si mesmo, mas sobretudo é um perigo aos demais. Importa aderir ativamente à idéia de que do auto-cuidado resulta prosperidade e segurança social, acima de tudo. Culpabiliza-se duplamente aquele que não só se descuida deste mister, mas ameaça aos outros todos.

Tanto as publicações quanto as palestras procuraram adequar-se ao público a que se dirigiam: familias, alunos maiores, alunos menores, professores, alunos ou alunas, funcionários. Tal preocupação fica mais evidente na estruturação da disciplina ginástica e higiene organizada, e por vezes ministrada pelos médicos do Departamento junto ao Parobé. A distribuição dos temas nos diferentes anos do curso elementar demonstra a preocupação didática com o grau de complexidade 
dos assuntos, mas também com a necessidade de repetição e efetiva assimilação dos mesmos, tratados cientificamente e vinculados a situações práticas:

"Curso elementar: $1^{2}$ ano: Asseio; vestuário; nutrição; efeitos do álcool e narcóticos; limpe-
za dos dentes, unhas, cabelos, etc. $2^{\circledR}$ ano: Necessidade de ar puro; ventilação; repouso e
sono; estrutura geral do corpo; cuidado da vista, do ouvido, unhas, cabelo, pele; efeitos do
álcool e narcóticos. $3^{2}$ ano: Vestuário higiênico; recapitulação das lições dos anos anterio-
res; primeiro tratamento dos talhos, contorções, fraturas, queimaduras e desmaios; efeitos
do álcool e narcótícos. $4^{\circ}$ ano: Vestimenta higiênica; estudo do corpo humano, pelo e sen-
tidos especiais; músculos, ossos, digestão, respiração, circulação; principios gerais de exer-
cícios fisicos; desenvolvimento da força; hábitos; efeitos do álcool e narcóticos" (Relatório,
1913:13-20).

A formação de atitudes e comportamentos de urbanidade através de conteúdos desenvolvidos junto aos alunos, que transparece no currículo acima, não ficou limitada à disciplina de ginástica e higiene. Os médicos sugeriram conteúdos também para o programa de ensino cívico do curso elementar para os alunos do $4^{\circ}$ ano:

"Civilidade e etiqueta. Cortesia: o cumprimento de um modo geral, o cumprimento com o chapéu e a cabeça, oportunidade do cumprimento, o aperto de mão, o sorriso, o bocejo, o espirro, o uso do lenço e do tabaco. Das visitas. As refeiçöes. A correspondência: estilo nas cartas" (Relatório, 1913:21).

Indiscutivelmente, novos saberes sustentaram a formação empreendida pelos médicos junto às escolas. Saberes que traduziam um novo tipo de indivíduo a ser formado pela escola. Saberes com o intuito de assegurar entre os formados outro saber-ser, outras representações e práticas, harmonizados com os imperativos do urbano. Um novo cuidado para consigo parece ser a tônica da formação empreendida. Acreditava-se então que a individualização das práticas, a incorporação dos hábitos eram o meio mais produtivo de assegurar a condutas comuns.

\section{A pedagogia do exemplo}

A adoção de procedimentos exclusivamente repressivos, como os castigos, fora julgada pedagogicamente insuficiente. Fazia-se necessário produzir convicções sinceras e encarnadas no que se refere à Higiene.

Para tanto, a pedagogia do exemplo foi perseguida insistentemente pelos médicos-educadores. Atuando junto aos professores, não sem resistências, sugeriram que estes deveriam constituir exemplos morais, função educativa essencial dos mesmos. Como sugere Freire Costa (1983:198), a moral higiênica via nas qualidades firmes, retas, justas e equilibradas do educador o antidoto contra a punição física.

Contudo, inúmeras vezes o Dr. João Pitta Pinheiro ressentiu-se da falta de apoio ou de resistências aos propósitos do Departamento de Saúde, denotando relações conflitivas com os professores, quem sabe até no que tange ao estatuto de educadores.

"É em extremo complexo o problema da Higiene Escolar, nem por todos compreendido, o que explica as dificuldades com que tenho lutado para a prática de certas medidas..." (Relatório, 1921:3). "Infelizmente, porém, nem todos conhecem bem o que seja um serviço 
de saúde, quando diz respeito às coletividades, não podendo avaliar as lutas para se pôr em prática uma medida de ordem higiênica e são por isso indiferentes, quando em uma coletividade a saúde não é alterada, ignorando que isso, em grande parte, é a conseqüência das medidas profiláticas executadas, a maior das vezes, silenciosamente" (Relatório, 1923:3) “...serviço que nem sempre é bem recebido, e exatamente porque, por sua natureza, muitas vezes põe em prática medidas em contrário aos interésses individuais, embora úteis à comunhäo" (Relatório, 1923:5).

Existem poucas informações relativas às disputas entre médicos e professores, bem como de ações dos médicos para barganhar o apoio deles. Contudo, de forma geral, é possível perceber a crescente legitimidade e importância conquistada pelo Departamento de Saúde.

Por vezes, essa legitimidade se assentou em impressões de visitas de agentes ligados ao campo do poder e agentes de expressão do campo médico (higienistas) recebidas pelo Departamento. Tais impressões eram amplamente divulgadas, num claro esforço por respaldar as ações empreendidas pelo Dr. Pitta Pinheiro.

Grande destaque era dado às impressões de professores da Faculdade de Medicina, uma vez que para o campo médico a Faculdade enquanto instituição legitimadora, constitui a autoridade de referência em matéria de conhecimentos e de práticas médicas legítimas (Hutmacher,1995: 66). Neste particular, o Dr. Pitta Pinheiro relatava a aprovação como também o caráter exemplar do Departamento de Saúde:

“o llustre professor Dr. Freitas de Castro, professor de Higiene da Faculdade de Medicina de Porto Alegre, já conhecedor do nosso Depto, nos solicitou a permissão para nele dar uma aula de Higiene aos seus alunos, doutorandos de 1925, solicitação imediatamente concedida com a anuência da Presidência, saindo os alunos satisfeitos de verem práticas que não julgavam existir em nosso Estado" (Relatónio,1925:4).

Professores e diretor da Faculdade de Medicina de Porto Alegre, em diferentes anos, aprovaram e assinalaram a orientação científica imprimida pelo Dr. Pinheiro ao Departamento, tornando-o eficiente e útil, modelo a ser seguido para uma verdadeira inspeção médica-escolar.

Em 1928, o Departamento recebeu a visita do Prof. J. Coelho, representante da Presse Médicale de Paris, junto da Academia de Medicina do Rio de Janeiro, que ratificou plenamente as ações do mesmo.

Tais indicações expressam, de um lado, um crédito significativo dos agentes médicos nas disputas com os demais agentes do espaço escolar, e de outro, um crédito implicado no jogo de interesses de legitimação dos médicos no campo social. A atuação em escola confirmava-se como estratégia privilegiada na conquista de sanção social.

É curioso, então, observar que progressivamente o Dr. Pitta Pinheiro passou a relatar o crescente apoio recebido no âmbito da Escola, destacando o respaldo a ele dirigido pelo seu diretor:

"foi a levação de vistas de todos os nossos companheiros de trabalho, que, aceitando, com consciência e na certeza de bem agir, todas as nossas indicações, aliás ditadas por uma Higiene verdadeiramente să, tomaram-se os nossos colaboradores eficientes" (Relatório, 1924:3). 


\begin{abstract}
"A Higiene não pede senão o que é de fato do bom senso e que tem o veredictum da prática; o que, porém, a Higiene exige da parte do seu Diretor é uma verdadeira consciência da verdade e uma coragem decidida para agir sem tibiezas e sem as conturbações de quem age por impulso dos outros. Neste particular satisfaz-se a minha consciência e anima-se a minha atividade tendo podido contar com o apoio da alta Administração desta Escola e apelo para que ele não me falte, certo de que a sua falta seria a esterilidade da minha ação, como Diretor da Saúde de uma Instituição notável e progressista como é a Escola de Engenharia de Porto Alegre" (Relatório, 1927:9).
\end{abstract}

Finalmente, cabe ainda indicar que o progressivo reconhecimento do Departamento de Saúde, intra e fora da escola, possibilitou a diversificação ainda maior de suas atividades. Estas passaram pela introdução de exames laboratoriais, aviamento de fórmulas, medidas profiláticas, até ações mais complexas como proposição de organização fisiológica do trabalho nas oficinas e serviços da Escola, introdução de gabinete psicotécnico e exames sustentados pela psicologia experimental.

\title{
Considerações finais
}

As práticas formativas da medicina social, no período em estudo, estiveram envolvidas em procedimentos complexos de produção de novas práticas, relacionadas a um novo comportamento peculiar à vida na cidade, traduzível por um modelo de "urbanidade" e civilidade, que se impunha consoante as próprias mudanças de tempo e espaço que se operavam então.

Este ideal de urbanidade veio ao encontro das perspectivas da ordem, da docilidade e da utilizabilidade produtiva, produzindo uma nova relação de cada indivíduo para consigo, o que foi possível pelas modificações e novas experiências com que as pessoas se depararam frente ao urbano e pelos processos formativos que as envolveram. É a idéia da constituição de uma nova sensibilidade urbana, capaz de atender às exigências da modernidade, de um novo modelo de civilidade (cf. Rago, 1993).

Uma extensa rede de saberes e poderes viabilizou-se pelo penetrante olhar médico nas mais diferentes instâncias do social, dentre as quais a escola profissional. Esse foi o lastro para a explicitação das estratégias individualizantes e coletivas que, materializadas nas instituições em que os médicos se fizeram presentes, incidiram sobre os indivíduos: vigiar-lhes a saúde, a higiene do corpo, roupas e alimentar tanto quanto infundir-lhes a valorização da limpeza e do amor próprio; modificar-lhes os hábitos, destruindo costumes enraizados, enfim, empenhar-se em tornar os espaços concretos limpos e asseados, conformadores de um gosto e uma estética higiênicos, socialmente partilhados.

A formação, ao incidir em experiências tendo em vista comportamentos higiênicos e consciência sanitária, permitiu às pessoas um conjunto de saberes relacionados ao deciframento de si mesmas, de seus corpos e de suas almas, exprimindo uma determinada tecnologia de si, através da qual produziram-se novas formas de pensar, sentir, agir.

A escola, efetivamente, parece ter confirmado seu potencial, especialmente nas décadas iniciais do nosso século, quando então a formação sanitária nela encontrou espaço institucional, locus privilegiado para sua efetivação. 
A ação destacada dos médicos é indiscutivel. Relacionaram-se, ora conflitivamente, ora interativamente, com outros agentes do espaço escolar. Conquistaram legitimidade suficiente para impor seus projetos e suas práticas, atribuindo uma forma aos processos formativos em que estiveram presentes.

Consciência sanitária e comportamento higiênico, propugnados pelos médicos higienistas, parece ter constituído marcas indeléveis da urbanidade e civilidade modernas.

\section{Bibliografia}

\section{Fontes primárias}

EGATEA, Revista da Escola de Engenharia de Porto Alegre. Anos de 1919 a 1933.

PITTA PINHEIRO, João. "Departamento de Saúde". Relatório da Escola de Engenharia de Porto Alegre. Porto Alegre, 1927. [s.n.t.]

Relatórios do Departamento de Saúde da Escola de Engenharia. In: Relatórios da Escola de Engenharia de Porto Alegre. Anos de 1919 a 1934.

\section{Fontes secundárias}

BOURDIEU, Pierre. Espaço social e poder simbólico. In: Coisas Ditas. Trad. de Cássia R. da Silveira e Deise Moreno Pegorim. São Paulo: Brasiliense, 1987.

- Réponses - pour une antropologie réflexive. Paris: Éd Séuil, 1992.

para uso particular).

CARVALHO, Maria Alice R. de, LIMA, Nisia V.T. O argumento histórico nas análises de saúde coletiva. In: FLEURY, Sonia (org.) Saúde Coletiva? Questionando a onipotência do social. Rio de Janeiro, Relume-Dumará, 1992. p. 117-156.

CHAPOULIE, Jean-Michel \& BRIAND, Jean-Pierre. A instituição escolar e a escolarização: uma visão de conjunto. In: Educação \& Sociedade. Campinas: Papyrus: CEDES, n. 47, abr.1994:11-60. Trad. Julieta B. R. Desaulniers.

DANDURAND, Pierre \& OLIVIER, Émile. A centralidade dos saberes e educação. In: Educação \& Sociedade. Campinas: Papyrus: CEDES, n. 46, dez. 1993:380-407.

DESAULNIERS, Julieta B.R. Formação, ou qualificação, ou competência... In: Veritas. Porto Alegre: EDIPUCRS, n. 149, 1993.

- A instituição: um lugar de produção do social. In: Véritas. Porto Alegre: EDIPUCRS, n. 15, 1995.

— Instituição escolar e a formação. 1993. Trabalho apresentado à 17י Reunião Anual da ANPEd (mimeo).

FOUCAULT, Michel. Histónia da sexualidade II: O uso dos prazeres. Rio de Janeiro, Graal, 1990a. $6^{a}$ ed.

- Microfísica do poder. Rio de Janeiro, Graal, 1993a, 11ª ed. - Curso no Collège de France 1980/81 p.133-141.Trad. Marisa Faermann Eizirik).

— Tecnologias del yo y otros textos afines. Barcelona, Siglo Veintiuno, 1990b.

- Vigiar e punir: nascimento da prisão. Petrópolis, Vozes, 1993b.10a ed.

FREIRE COSTA, Jurandir. Ordem médica e norma familiar. Rio de Janeiro, Graal, 1983.

HERSCHMANN, M. e PEREIRA, Carlos A. M.(org.). A invençāo do Brasil Moderno: medicina, educação e engenharia nos anos 20-30. Rio de Janeiro, Rocco, 1994.

HUTMACHER, Walo. Para uma análise das instituições escolares. In: NÓVOA, António (org.). As organizaçöes escolares em análise. Lisboa: Dom Quixote, 1995. (p.13-42).

LARROSA, Jorge. Tecnologias do eu e educação. In: SLVA, T.T.(org.). O sujeito da educação: estudos foucaultianos. Petrópolis: Vozes, 1994. (p.35-86). 
MARQUES, Vera Regina Beitrão. A medicalização da raça: médicos, educadores e discurso eugênico. Campinas, SP, Editora da UNICAMP, 1994.

RAGO, Luzia Margareth. Politicas da (in)diferença: individualismo e esfera pública na sociedade contemporânea. In: Anuário do Laboratório de Subjetividade e Politica-Movimentos Sociais/Linhas de Fuga. Ano II, v.II, 1993. UFF, Rio de Janeiro. (p.11-29).

STEPHANOU, Maria. Forjando novos trabalhadores: a experiência do ensino técnico profissional no Rio Grande do Sul (1890-1930). Porto Alegre, Dissertação de Mestrado. Faculdade de Educação (UFRGS), 1990.

- Formar o cidadão fisica e moralmente: médicos, mestres e crianças na escola elementar. In: Educação, Subjetividade \& Poder. Porto Alegre: Núcleo de Estudos sobre Subjetividade, Poder e Educação, Programa de Pós-Graduação em Educação da UFRGS; Ijui: Editora UNIJÚ, v.3, n.3. jan./jun.1996 (p.59-66).

TANGUY, Lucie \& ROPE, Françoise (org.) Savoir et compétences - de l'usage de ces notions dans l'école et l'entrepise. Paris: L'Harmattan, 1994. 